\title{
The Research on the Educational Pattern for the Chinese Athletes-the Combination of Education and Sports
}

\author{
Jing Gao \\ School of Physical Education \\ Changzhou University \\ Changzhou, China \\ e-mail: Bloomingflower@tom.com
}

\begin{abstract}
The educational pattern of "education plus sports" is not only a helpful supplement to the cultivation modes of competitive sports talents under the nation-governed system, but an important guarantee for the athletes' rights to accept intelligence and education. Adopting this pattern is vital to the sustainable development of competitive sports in China. However, at present, the intellectual training for the athletes in sport system is independent of the common social educational system and the so-called "education plus sports "model is not a real combination of education and sport in the true sense. Based on the present situation in the athletes' education, it is proposed and suggested: to explore and construct a diversified systems for the intellectual education of athletes, to set up and improve the rules and regulations, to strengthen the supervision towards the education of athletes.
\end{abstract}

Keywords-education plus sports; athletes; competetive sports; educational pattern

\section{INTRODUCTION}

The pattern of "education plus sports" is a special educational pattern developed by the administration of sport and education and the aims of this policy is to cultivate high quality competitive sports reserve talents. This "peopleoriented" policy is issued under the guidance of the scientific concept of development in new era of China. To construct a novel sports training system which makes the combination of competitive sports and social education is an important route to cultivate high level athletes with higher intellectual qualities and global view. After 20 years of exploration and research on the pattern of "education plus sports" in China, we have harvested some good effects. However, due to various reasons, there were still many contradictions and difficulties in the practical operation, resulting in many inadequacies in the process to cultivate the competitive sports talents in China.

\section{THE DEFINITION OF THE PATTERN OF "EDUCATION PLUS SPORTS"}

The pattern of "education plus sports" is a stage

Fund Projects of Administration of Sports in Jiangsu, China (No. ST13300229) achievement of the development of Chinese athletic sports and education reform process. It is a novel conception to cultivate high level competitive sports athletes in China, based on the condition that at present, the sports administrative institutions and education administrative institutions are two independent units. This pattern is established by the cooperation between two administrations in order to cultivate high-level athletic sports talents with the comprehensive development. Moreover, it is a "peopleoriented" harmony system under the guidance of the scientific concept of development in new era of China.

The specific expression for this pattern is: Guided by the scientific concept of development, praised by the all-round development of person, cooperated and fulfilled by administrative unites, complimentary advantages supported in resources, diversified in its forms, the pattern of "education plus sports" is established under the Macroregulation of government. The administration of education takes the responsibility of control the studies and partly sports training of athletes, as well as the administration of sport takes the responsibility of management of sport games and clubs( including profit professional sport club and nonprofit community competitive sport club).This harmony training system of high-level athletic sports talents is based on the endeavors of society, company, and market; particularly, the efforts of sport and education administrations; development of competitive sports as well as implement of comprehensive social sports; is consist of many stages, such as Elementary school, middle school and college school.

\section{THE BACKGROUND AND HISTORY OF THE PATTERN OF "EDUCATION PLUS SPORTS"}

\section{A. The Disadvantages of the "Nation Governed"System Promotes the Formation of the Pattern of "Education Plus Sports"}

Since 50s last century, the mechanism of social sports in China is governed by administration and executed in a highly concentrated mode, under the planned economy. That is called "nation governed system". With the development of 
this system, the "pyramids" type sports training system with three-level talent training modes in China had been formed under the administration-dominated sports leadership: the national team occupies the top of the pyramid; the teams of provinces, autonomous regions and municipalities, the PLA and industry collaboration team lie on the middle of the tower; base of the bases of the tower includes amateur sports schools, children's sports schools, sports schools of traditional games, experimental schools to bring up excellent talents, and so on. Indeed, this training mechanism made a large of athletic sports talent and huge of contribution to the development of China Athletic sports. However, the disadvantages of this system are more and more obvious with the development of current sociality and the rationality of this system is increasingly questioned by the requirement of the socialist market economy development law. The main difficulties in this system are: 1. for a sports reserve talent grew up eerily in child for specialization of movement training, lost his opportunity to accept full, comprehensive and compulsory education; 2 . Due to the low success rate in competitive sports, a large number of athletes have to face employment difficulties after they retired;3.For the three is single talent training channel, the shortage of reserve talent is serious; 4. With the development of social structures, the Chinese parents expect a diversified trends for the future development of their kids, and they are reluctant to send their children to children's sports schools. All of this will seriously affect the sustainable development of competitive sports in China and forced us to rethinking about athletes ' culture education issues.

\section{B. The History of the Pattern of "Education Plus Sports"}

In order to reduce the damages of "“nation governed system "to the intellectual education of athletes, resolve the nationwide system impact on athletes, the State Education Commission and the National Sports Commission jointly released a notice in $1987,<<$ the notice of work on part of the ordinary colleges and universities recruit high level sports reserve talent $>>$, for the first time, made recruiting some elite sports reserve talents to universities being the agenda of school physical education. In 1990, the State Education Commission and the National Sports Commission once again jointly issued the regulations of school physical education and proposed that after approved by the State Board of education, the general institutions of higher learning cultivating can train excellent reserve athletic talents. In 1995, the Ministry of Education issued the notice said that in part of ordinary colleges and universities explore to occupy high-level sports teams and the progressive realization of the aims of the State Board of education team for the presence of World University Games. and for the first time regulate institutions on training high level sports athletes, the number and scope of admissions, recruiting conditions, recruiting methods, the requirement of teaching and management of the students; In 2000, State General Administration of Sport pointed out in the annual platform for sports reform and development from 2001-2010 and proposed "gradually transition to college sports teams, to provide a more convenient entrance, study conditions for elite athletes." In July, 2002, the CPC Central Committee and the State Council published on further strengthening and improving the physical education in the new era and pointed out "work hard on athletic intellectual education", "improve the scientific and cultural quality of sports teams." In 2005, the Ministry of education, General Administration of sport said in the comment "further strengthening the construction of high level sports teams in ordinary colleges and universities" "strengthen the pattern of "education plus sports", Colleges should enhance cooperation with the sports administration and take a variety of forms and complement the advantages, share the resources, Take the College as the main role, gradually improving the excellent sports talents training mechanism in college, middle and primary schools; the institutions of higher education should adopt positive measures to care and help middle and primary schools carry out training of excellent reserve athletic talents. Since then, from college to high schools and elementary schools, the pattern of "education plus sports" was put into practice in national scope.

\section{The OngOING DeFECTS OF THE PATTERN OF "EDUCATION PLUS SPORTS"}

In 2003, the 23 Session Universidad, the team of MOE on behalf of China for the first time, scored good result of the second total gold medal, especially, students athletes $\mathrm{Hu}$ won has men hundred meters champion, following "Tsinghua mode" training mode. This success made new contribution to the improvement of China students sports level and exported a new route of the pattern of "education plus sports "with Chinese features. It confirmed the present pattern and strength the route of "education plus sports" for training excellent athletes reserve talent .But, if we see from the effect of training talents, the quality of talent cultivation still luck a substantive change.

\section{A. "Sport" and "Education" are Relatively Independent Unites}

In China, the educational system and the sport system are two independent systems. The athletes training supplied by Sport system is independent of the education system, the education system also cannot be solely response for the training tasks of high-level competitive sports talent. In China, if an athletic children was found, he will be transferred to the sports school and be trained and then go to specialized sports schools, sports teams, which belongs to athletics departments' .Therefore, these kids often absent from the basic education classes, and luck of theory of science and culture. Additionally, from the related experience of current some college, there appeared some fake combination: due to sports system are eager to resolve some current problem produced by the mechanism of a competitive sports, for example, the contradictions of the studying and training for athletes, perspectives of the athletes, and so on. College often pursued short-term target and local interests, then, under the conditions of both sides are favorable, College appeared many affiliated athletes and retired athletes. This type of the pattern of "education plus sports is not the real meaning of sports and education converging. The occurrence of this situation, made the 
University system's athletes lacking independent game systems, made the colleges did not really act the role of training high level athletes.

\section{B. Mutual Checks of System and Mechanism in the Pattern} of "Education Plus Sports"

1) The policy of the pattern of "education plus sports" lack standard ability and continuity in many areas, mostly stays in feelings communication between sports and education administrative sector, exists many randomness in practical operation;

2) The existed mechanism has some limitations in athletes entrance, and studies, the related policy offers lack attraction;

3) The perspectives of most amateur training athletes are hard to cope with, it seriously destroy the enthusiasm of parents sending their children to participate in amateur training, directly interference with selecting promising talents.

\section{The Contradiction between Learning and Training Needs to be Cracked}

Combination of learning and training is a fundamental requirement for high level athletes, but the contradiction between learning and training has always been a very tough one and there is still no completely effective solution until now. In addition, most colleges and universities often increase learning and training time in holiday, so the students cannot find plenty of time to study besides sport games and training.

\section{The DeVeloping StRategy OF the PATtern OF“EDUCATION PlUS SPORTS”FOR CHINESE ATHLETES 'INTELLECTUAL EDUCATION}

\section{A. Strengthen collaboration mechanism between sports system and the education system}

From the Government administration's point of view, combining sports and educational system and cultivating excellent reserve athletic talents and meeting the social requirement of the "four-have" talents, following the rules of training, following the rules of educational law and accepting systematic education, performing the advantages of sports and education sector, is the basic mode to cultivate sports reserve talents in China. Firstly, the department of education should change the past examination-oriented educational concept, establish the real concept of the quality education, regards physical training and sports-related hobbies and culture education equally important, and support these activities in terms of human, material, financial and others. Meanwhile, district, county-level amateur school can do their amateur training in some middle and primary school with good material conditions (sports reserve talents in traditional sports schools, pilot schools, etc.), the coaches enter the appropriate primary and secondary schools to engage in training. Government departments of education and sports should improve management, increase financial input, arouse the enthusiasm of the associated schools, and evaluate their performance on a regular basis.

\section{B. Gradually Forming the Culvating System for the Ssports Reserve Talent including Primary-Middle- College School Periods}

At the stage of basic education, we promote the amateur training as well as culture learning in the middle and primary schools as the main text. We reform the current educational system for elite athletes from the strategic perspective of athletes. We gradually escape from the " vicious circle ", that is sports system only do competitive sports, but do culture education, put the part of basic education in competitive sports system into the social education system.

At the stage of high school education, on the basis of basic education for the athletes, we gradually change the past modes that the Sports Technology College merely perform sport education, carry out cultural and educational work according to the two main lines of senior secondary education or secondary vocational and technical education. Concretely, we can set up "high school" in the newly formed School of competitive sports or establish class of "athletic "at every high school. In terms of roll and academic, we can adopt the credit system and flexible credit system; In terms of content of teaching, we can simplify the teaching content, according to basic required content of general high school education; In terms of teaching method, we can adopt flexible and diversified educational methods and modern teaching methods based on realities and needs. Meanwhile, to meet the needs of some athletes' employment after high school, we can develop secondary vocational and technical education for athletes, enabling them to obtain the appropriate social skills.

At the high education level, first of all, we should set up the new school of competitive sports where physical education, competitive sports, sports science and technology resources are integrated effectively and utilize the local advantages in physical education, sports, sports science and technology resources, turning it into an entity of teaching, training, scientific research. Secondly, positive measures should be taken (such as provincial educational administration plan the layouts of local sports teams after research, support local ordinary colleges and universities host high level sports teams, make efforts to broaden the channels of college admissions of high-level athletes. At the same time, universities should be actively explored, take various effective measures, make the elite athletes in colleges and universities a " four modernizations "member(that is, students status for the school outstanding athlete, student rolling management, flexible academic time, scholarships as wages) so as to improve the quality .

\section{To improve rules and regulations, standardize educational management of athletes.}

First of all, we should continue to strengthen or develop policies and regulations to protect athletes ' position and ensure the necessary time for the athletes to learn culture. Secondly, we should establish strict regulatory framework, 
develop a range of rewards and punishments and additional measures such as to ensure the implementation of the various policies, rules and regulations. Thirdly, we should take effective measures to step up inspection of law enforcement efforts, any ignoring the law for athletes ' culture education issues, lax law enforcement should be corrected. We should put the issue of cultural and educational work for athlete into the legal system really.

\section{To strengthen the supervision of intellectual training for the athletes}

A key factor to strengthen the supervision of intellectual training for the athletes is to cultivate a high-quality cultureteaching team. For this purpose, we should pay attention to improve their ideological and professional qualities, and continue to improve the conditions of their teaching activities and the material supplies. Meanwhile, the knowledge team for the athletes should be active in teaching activities, optimizing the teaching contents and implementing the completely quality-oriented education, striving to improve the overall level of outstanding athletes, according to the specific rules of learning and training for the athletes.

Another key element to strengthen the supervision of intellectual training for the athletes is to improve the cultural quality of coaches and their awareness of importance of athletes 'cultural level. As a result, coaches engaged in high, and intermediate training must have college level majored in sports, according to the regulation of State General Administration of sport, otherwise shall not be on duty; To establish and perfect coaches training, and assessment, and appointment system, constantly improve the overall quality level of coaches team; to take the culture learning of the sports teams as an indicator to evaluate the scores of coach team, to establish rational promoting system which integrate evaluation of game scores and athletes culture learning scores, so as to further increase the coaches' awareness of importance of elite athletes 'cultural level, and so on.

\section{ACKNOWLEDGMENT}

This work was supported by Administration of Sports in Jiangsu under the grant ST1330029.

\section{REFERENCES}

[1] http://www.people.com.cn/item/flfgk/gwyfg/1987/206009198703.htm 1, accessed April 02, 2015

[2] http://www.moe.edu.cn/publicfiles/business/htmlfiles/moe/moe_620/ 200409/1436.html, accessed April 02, 2015.

[3] http://www.chinalawedu.com/news/1200/22598/22615/22792/2006/3/ sh1395554402613600216610-0.htm, accessed April 02, 2015.

[4] http://www.sports.cn/politics/bmzc/2000-12-15/2313328.html, accessed April 03, 2015

[5] http://www.jiangsu.gov.cn/jsgov/szfzsjg/tyj/201209/t20120920 1440 42.html, accessed April 03, 2015.

[6] http://www.eol.cn/article/20051014/3155676.shtml, accessed April 03, 2015.

[7] Xuan-jian Ma. Research on formation and development combining sports with education, Journal of Shanghai physical education insititute, 2005,29.02:1-8.
[8] Xue-qian Liu. A study of the construction of a cultural education system for excellent Guangdong athletes, Journal of physical education, 2006,13.03:111-114. 